New laboratory procedures are used for evaluating critical dosage, bait refusal, and speed and variability of action of five poisons against three rodent species. Warfarin is not excelled by other compounds tested, but some others are about equal to it against some species.

\title{
Laboratory Studies of
}

\section{Five Anticoagulant Rodenticides}

\author{
WAYLAND J. HAYES, Jr., M.D., Ph.D., and THOMAS B. GAINES, B.S.
}

E ARLIER studies on warfarin have emphasized the difference between the newer, anticoagulant rodenticides and the older, quickacting poisons (1). It was evident at the beginning that laboratory tests used for quick-acting rodenticides were not applicable to the newer poisons without modification. Hence, development of a suitable laboratory method for rapid evaluation of the slow-acting rodenticides was an important part of the present studies. The procedures devised, as well as the results obtained with respect to required dosage, bait refusal, and speed and variability of action, are reported in detail.

\section{Materials and Methods}

All wild rodents tested were caught by hand in the field and then held in the laboratory on a diet of laboratory chow $(A)$ for a minimum of 2 weeks before testing. During each test, the rodents were kept separately in cages of the Army Medical School type. They were offered free choice of $(a)$ unpoisoned, ground labora-

Dr. Hayes is chief of the Toxicology Section, and Mr. Gaines is a pharmacologist with the Technical Development Laboratories, Technology Branch, Communicable Disease Center, Public Health Service, Savannah, Ga. tory chow and $(b)$ yellow cornmeal (maize) containing an appropriate concentration of the rodenticide under test. Water was available at all times. Yellow cornmeal was chosen as the food in which to offer the poison because it has proved to be the most generally acceptable, inexpensive bait under field conditions. Laboratory chow was used as the poison-free food because it was the food to which the rodents were conditioned before the tests began and because it is as similar as is practically possible to the mixed diet which rodents receive in nature. Providing the two foods simulates field conditions, as it is generally impractical under field conditions to offer poison to rodents in the same kind of food as that to which they are accustomed. In fact, an effort should be made to offer a bait which the animals will prefer to their ordinary food.

Figure 1, part a, shows cups for offering a. choice of food in place at the back of a cage. These cups, with special lids to minimize spillage, are available commercially. They are satisfactory, but experience has shown that wild rats overturn them occasionally. Spring clips were designed to hold the cups firmly in place (fig. 1, parts $\mathrm{b}$ and c). These clips, made without special tools from 24-gauge galvanized. sheet metal, can be bolted to the back of each cage. The food cups can be easily removed 
from the clips for weighing, but rodents cannot move them.

These cups, the smallest commonly available from dealers, are too large to use with mice since strong animals frequently get into them, while mice weakened by poison cannot reach the food at all and are thus starved. Cups made from 2-ounce ointment cans proved satisfactory for mice. A hole seven-eighths of an inch in diameter was cut in the center of the metal lid, and the top portion of the lid was then depressed in a conical form similar to that of the larger, commercial models shown in the figure. Special holders for the small cups were not necessary even for wild mice. A disk of $1 / 4$-inch mesh hardware cloth was put in each cup to prevent mice from scratching food out. As an added precaution, fresh paper was used in the tray of each cage so that any spilled bait could be detected.

The following rodenticides were studied: warfarin, 3-(d-acetonylbenzyl)-4-hydroxycoumarin ; coumachlor, 3-(d-acetonyl-4-chlorobenzyl)-4-hydroxycoumarin; Pival, 2-pivalyl-1,3indandione; PMP, calcium salt of 2-isovaleryl1,3-indandione; and Diphacinone, 2-diphenylacetyl-1,3-indandione $(B-F)$. Each compound was tested against adults of one or more of the following species: the Norway rat, Rattus norvegicus; the roof rat, Rattus rattus; and the house mouse, Mus musculus. A short supply of animals prevented testing coumachlor against mice or Diphacinone against roof rats or mice.

The dry, poisoned baits were prepared by mixing appropriate amounts of the rodenticide into the bait with an ordinary kitchen-type electric food mixer. For low concentrations of poison ( $50 \mathrm{ppm}$ or less), the technical grade compound was weighed out carefully on an analytical balance and then, with a mortar and pestle, thoroughly mixed with cornstarch in the proportion of 1 part rodenticide to 99 parts cornstarch by weight. The amount of this rodenticide-cornstarch concentrate required to give the desired concentration of poison in a selected weight of finished bait was weighed out and mixed thoroughly with about onefourth the necessary weight of cornmeal. The remainder of the cornmeal was then added and mixed to give the final concentration of poison
Figure 1. Equipment for offering a choice of baits to caged rodents.

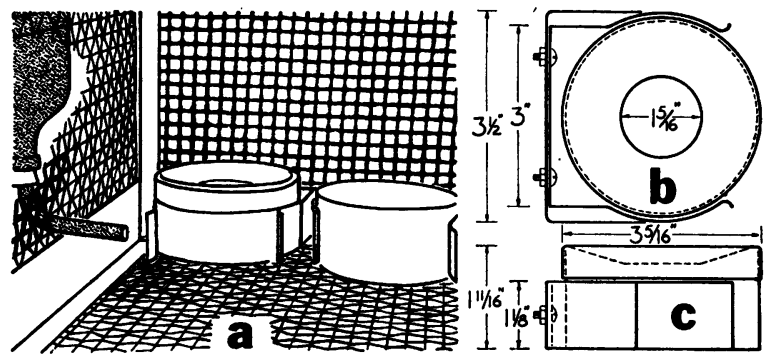

Part a, food cups held in place by metal clips (cover of one cup removed). Part b, top view of metal clip and food cup. Part c, end view of same clip with food cup in place.

to be tested. For the higher concentrations of rodenticide (100 ppm or more), the procedure was the same except that the proportion was 1 part rodenticide to 19 parts cornstarch. Each separate mixing with the cornmeal required at least 15 to 20 minutes. Coarse, degerminated cornmeal of a quality suitable for cooking was used in all the tests.

Each rodenticide was tested in several of the following concentrations, which form a geometric progression with a factor of one-half: $800,400,200,100,50,25,12.5,6.3,3.1$, and 1.5 ppm. Chemical analyses showed that it was possible to obtain these concentrations with an error of $0.5 \mathrm{ppm}$ or less. Ten rodents ( 5 males and 5 females, when possible) were usually used for each test; more than one test was frequently made, especially at the lower dietary concentrations. Each rodent was offered the poison (as well as poison-free food) for a maximum of 40 days. Surviving animals were maintained on laboratory chow until they died or until their survival was assured. The time of death was recorded in all instances.

During the tests, the intake of poisoned bait and of poison-free food was recorded daily for each animal. The animals were weighed once a week. These measurements made possible the calculation, on a milligram per kilogram basis, of the total dosage of rodenticide ingested by each rodent. They also made possible direct comparison of the amount of poisoned bait and of poison-free food taken by each rodent. Bait refusal is conveniently expressed as the average percentage of the total daily 
diet during the exposure period which was poison free. As already mentioned, this percentage was intentionally suppressed by offering the poison in an attractive bait. However, the choice of diet used in the test permits rodents to refuse poison completely (bait refusal $=100$ percent) without undergoing any hunger.

Under practical conditions of use, it is characteristic of poisoning by anticoagulant rodenticides that most of the animals die relatively soon after the first one, but a few linger on for many days especially when the poison is fed at a low concentration. (The initial delay is explained by the pharmacological action of these compounds.) Values skewed in this way tend to be normalized by logarithmic transformation. Therefore, the logarithms of the survival times were used to calculate the geometric mean and 95 percent confidence limits. The antilogarithms of the resulting values were then plotted (together with the observed values) against the concentration of rodenticide in the bait. In all instances, the calculations were based solely on animals which died. However, in those instances in which one or more animals survived the test, the upper 95 percent confidence limit was not plotted because in this situation it is not realistic.

The critical dosage is defined as the smallest average dosage killing a species so rapidly that the upper 95 percent confidence limit for that and all higher average dosages is 45 days or less. (Usually, the critical dosage was identical to the smallest average dosage which killed all rodents tested.) The dietary level of poison consumed by those rodents which received the critical dosage is designated the critical concentration.

The average bait refusal of rodents offered four times the critical concentration is selected as the value for comparison of one species with another and of one poison with another. The factor of 4 is used so that comparisons may be made for dietary levels suitable for field use. It has been observed, within the geometric progressions of dosages studied, that a factor of 4 compensates adequately for irregularity in consumption of bait and other ill-defined variables which characterize the use of rodenticides in the field. Thus, a factor of 2 is too small, and a factor of 8 is unnecessarily large. For the same reason, the geometric mean for timeto-kill (in days) for rodents offered four times the critical concentration is selected as a comparative value for the speed of action.

The variability of action is defined as the difference (in days) between the geometric mean and the upper 95 percent confidence limit of the time-to-kill for rats fed four times the critical concentration. This method of expressing variability of response gives practical information about the period necessary to kill a species with a particular poison. The variabilities of dosage and bait refusal tend to be correlated; however, they are of less practical interest and are not presented in this paper.

\section{Results}

The results in regard to dosage are presented for all compounds and all species tested in table 1. Corresponding results on bait refusal and speed of action are given in figure 2. Some indication of the variability of action of each poison also may be inferred from the figure.

The data in table 1 indicate that the critical dosage is truly characteristic of the action of a particular poison in a particular species. For example, the critical dosage of warfarin for wild Norway rats was $4.2 \mathrm{mg}$. $/ \mathrm{kg}$., corresponding to a concentration of poison of $12.5 \mathrm{ppm}$; yet even over the wide range of concentration of poison of 1.5 to $50 \mathrm{ppm}$ the average dosage showed the narrow range of 2.3 to $6.8 \mathrm{mg}$. $/ \mathrm{kg}$. The critical dosage of warfarin for the roof rat was $18.1 \mathrm{mg} . / \mathrm{kg}$., a value distinctly different from that for the Norway rat.

The dosage of any of the rodenticides tested necessary to kill the three common commensal rodents is small; however, as shown in table 1 and in figure 2, the three species differ strikingly in their response to the rodenticides. In general, the Norway rat was most susceptible, as judged by dosage and survival time, and the roof rat was least susceptible. Furthermore, the roof rat tended to show greater variability of response than the Norway rat. The house mouse resembled the Norway rat in susceptibility but the roof rat in variability. Thus, the results determined for one species cannot be applied with precision to another. 
Table 1. Dosage of anticoagulant rodenticides consumed by rodents when offered

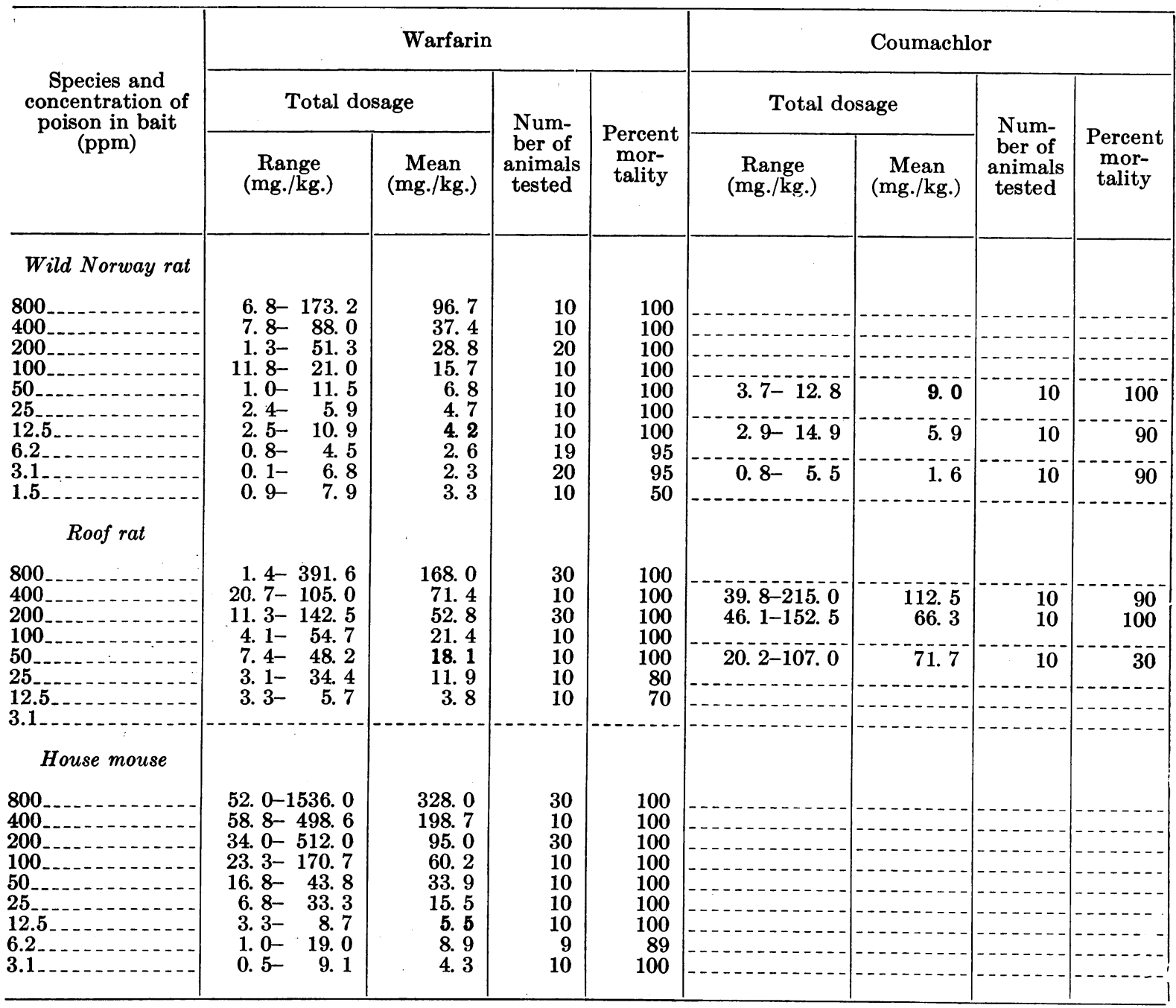

NoтE: Critical dosages, as defined in text, are in boldface type.

There is evidence, both from a high degree of bait refusal and from an increase in bait refusal with increasing concentration, that PMP is detected by wild Norway rats and by mice. There is some evidence, from an increase in bait refusal with increasing dietary concentration on the first day of exposure, that both species of rats may detect the higher concentrations of warfarin. However, all three species tended to adjust to the flavor of the rodenticides so that secondary bait refusal was not significantly greater and was occasionally slightly less than the corresponding primary bait refusal. (Secondary bait refusal, also called "bait shyness," consists in a learned response frequently based on illness induced by a poison.) Thus, the anticoagulants contrast strongly with the fastacting rodenticides, which lead to more serious primary bait refusal and especially to almost complete secondary bait refusal. This observation does not contradict the fact that, as rodents became progressively poisoned with anticoagulants, they ate less and less food of both kinds.

Within groups in which all animals died, special analysis was made of the animals which survived more than 14 days. Study of the individual records showed that, with rare exceptions, all animals of the three species which survived more than 2 weeks took substantial 
poisons at different concentrations in bait and with a free choice of unpoisoned food

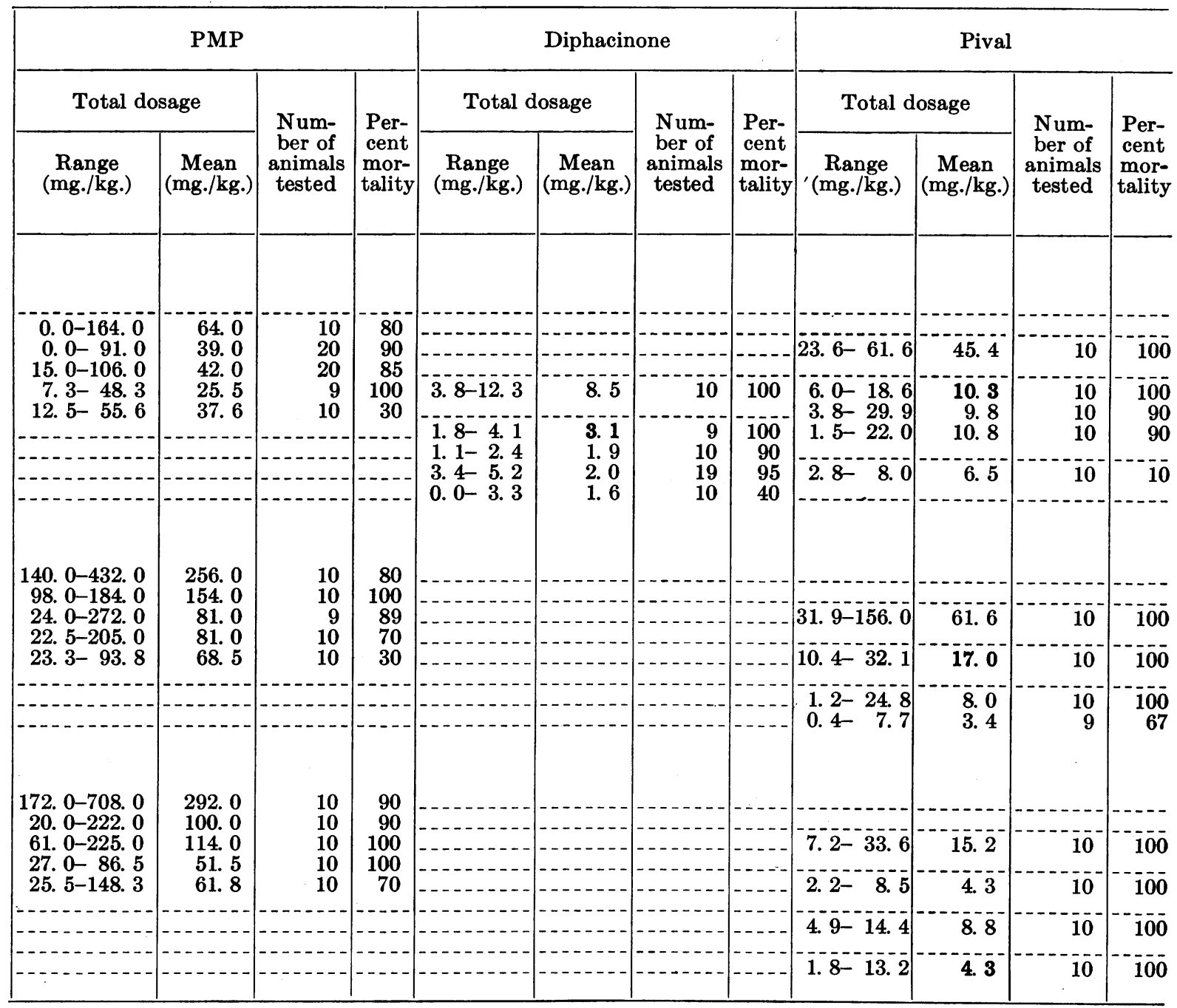

Note: Critical dosages, as defined in text, are in boldface type.

amounts of poison; in fact, their longer survival permitted them to take, on the average, slightly greater total dosages than corresponding rodents which died sooner. Further, most of the rats and mice which survived more than 2 weeks took poison promptly when it was first offered. The few exceptions were refusals of PMP for 21 days or more, with the result that the animals did not receive an adequate dosage. It must be concluded that the unusually long survival periods of a few rodents exposed to effective bait concentrations usually were caused by unexplained properties in the metabolism of the individual animals and not by their failure to ingest poison.
The time necessary to kill the first rat in a group was remarkably similar for the poisons studied irrespective of the concentrations at which they were fed. This is explained by the mode of action of the compounds. Death is the result of hemorrhage following the loss of "prothrombin" activity in the blood. A minimum period of time is required for the activity to be reduced and then for adequate hemorrhage to occur. This is true even in animals which suffer cerebral hemorrhage as well as those which die in the usual way from shock following more extensive bleeding at less critical sites. It appears from figure 2 that the average survival time of wild Norway rats fed 
warfarin is not shortened to a practical degree by increasing the concentration of poison in bait above the minimum necessary for effective control. The same is probably true of other rodents and other anticoagulants; however, application of the principle to roof rats fed warfarin was obscured because of the great variability in the response of that species and in other instances because few of the bait concentrations tested were above that which is minimal for control.

Analysis of the data revealed no differences in susceptibility based on sex in any of the three species studied. None of the females was pregnant. Earlier tests have shown that pregnant animals exhibit an increased susceptibility (1).

Figure 2. Bait refusal and survival time of rodents offered unpoisoned food and various concentrations of rodenticides in bait.
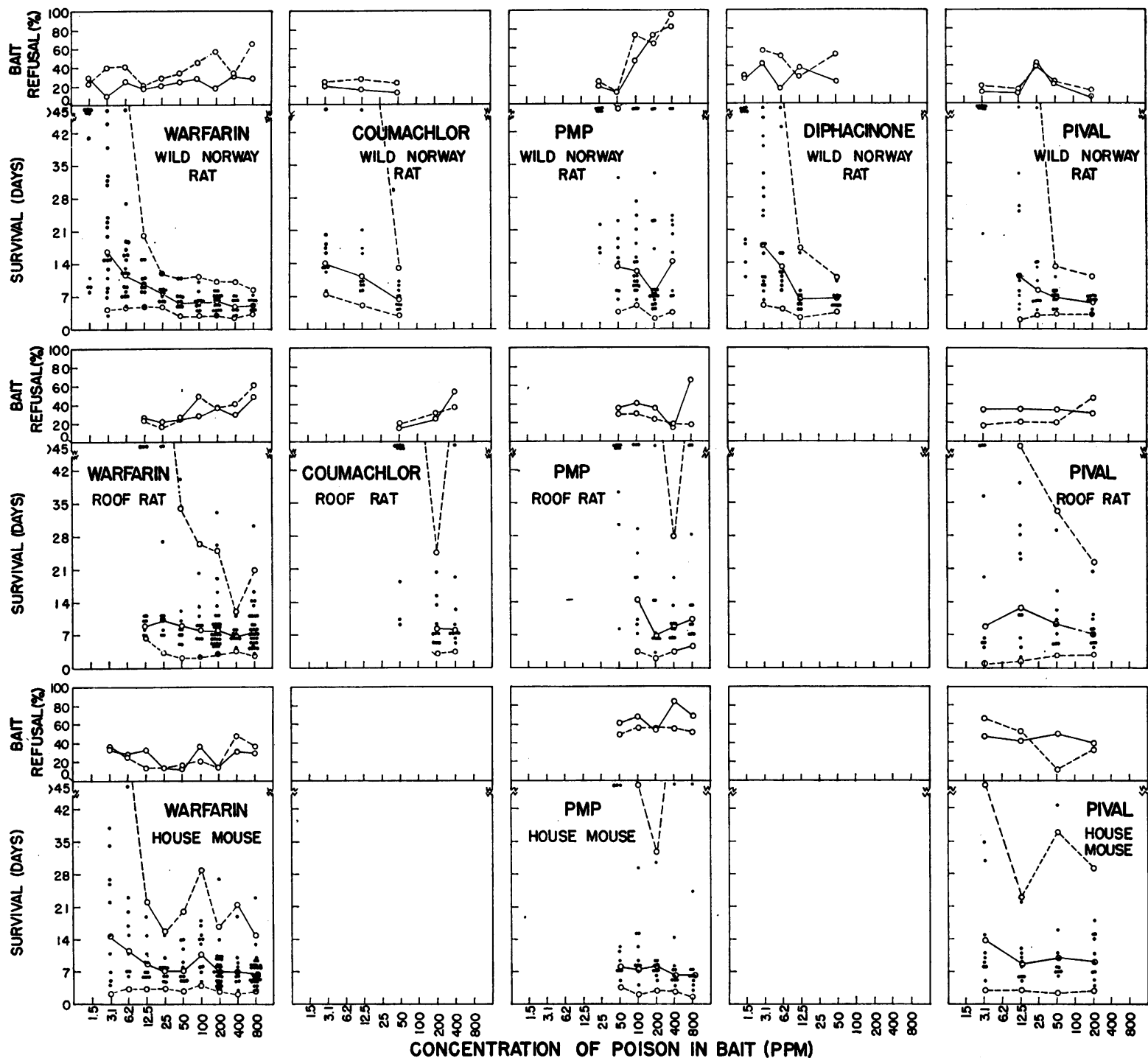

BAIT REFUSAL (percentage of total food intake which was unpoisoned) : Dashed line, first day of experiment. Solid line, entire experiment.

SURVIVAL TIME: Dots, survival time for each rodent. Open circles connected by solid line, geometric mean for the time of death of rodents that died; open circles connected by dashed line, 95 percent confidence limit. 
Table 2. Critical dosage, bait refusal, speed of action, and variability of action characteristic of anticoagulant rodenticides

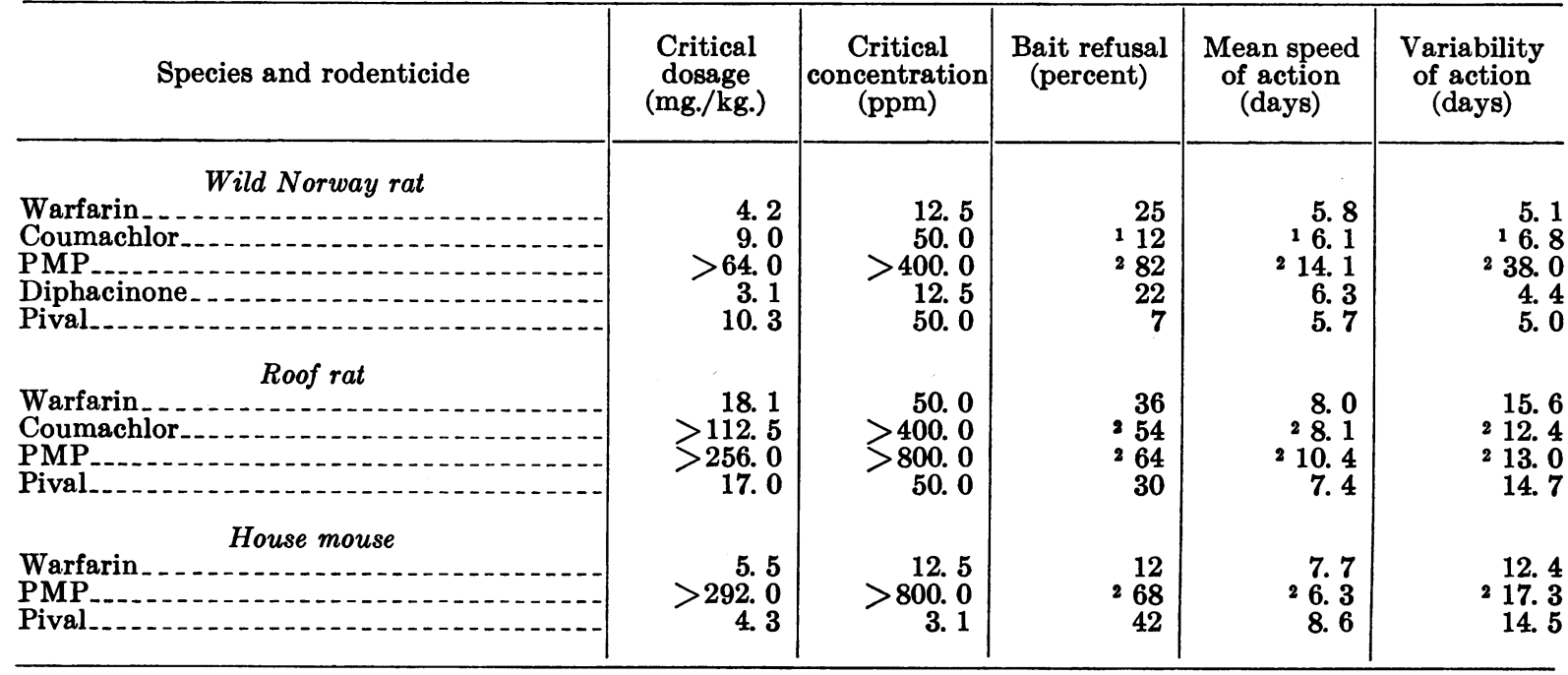

1 Determined at the critical concentration because no test was run at four times the critical concentration.

2 Determined at the highest dosage tested because a dosage satisfying the definition of critical dosage was not found.

Note: For each characteristic, a low value is favorable.

Of the several poisons tested, only warfarin was tested against Wistar strain albino Norway rats, with the same experimental procedures. The results (tabulations not shown) were so very similar to those for the wild Norway rat that for practical purposes they could be substituted for them.

A few new observations on pathological changes caused by warfarin supplement those reported earlier (1). A very few rodents poisoned by warfarin show paralysis of the hindquarters for a variable period before death. In every instance encountered so far, this sign of illness has been explained by the finding at autopsy of limited hemorrhage in the central nervous system. A few other rodents die rapidly without the development of paralysis as the result of more massive cerebral hemorrhage.

Mice show a distinctly different pathological condition from that observed in the two species of rats. Slightly more than half of 105 mice examined showed a profuse, thin, serosanguineous exudate into the pleural cavity. Both the character and location of this exudate differ from anything consistently seen in rats.

The results of this study, summarized in table 2, appear to justify the following conclusions.
The performance of warfarin against the commensal rodents was not excelled by the other anticoagulant.compounds tested. Diphacinone was about as good as warfarin against wild Norway rats. Pival was about equal to warfarin against roof rats and mice but, like coumachlor, somewhat inferior against wild Norway rats. In comparison with the other rodenticides tested, PMP was distinctly inferior against all three species of commensal rodents.

\section{Discussion}

The method of laboratory testing described is adapted especially to the bioassay of rodenticides in instances in which both the toxicity and the acceptability of the material are under study. Use of the method for estimating proper concentrations of slow-acting poisons against a given species of rodent should obviate field testing of inappropriate concentrations.

Several papers dealing with testing of anticoagulant rodenticides have been published (2-12). However, we believe that the method described here yields more complete and more practical information than do earlier methods.

Laboratory tests in which the rodents are fed 
poison on alternate days only were considered. Norway rats fed warfarin on alternate days survived slightly longer than those fed the same concentration of the poison ad libitum because there was a delay in acceptance of the poisoned food when it was offered on alternate days. Crabtree (2) and Bonnet and Gross (6), in tests with warfarin against Norway rats, found that the result was the same whether the rats were fed the poison ad libitum or on alternate days. On the other hand, Rattus hawaiiensis survived twice as long when fed warfarin on alternate days as when fed ad libitum (6). In any event, when poison is offered on alternate days only, the test is complicated by baiting problems so that it becomes more difficult to know which variables are being measured.

Every effort should be made to determine rodenticide dosages which are effective and, at the same time, as cheap and safe as possible. The use of unnecessarily high dosages may compensate in part for careless mixing of the bait, poor bait distribution, and inferior technique generally, but adds to the expense and to the hazards inherent in the use of rodenticides.

In one of the original studies (13) on the analogs of 3, 3-methylene bis (4-hydroxycoumarin), the compound now known as warfarin was shown to have less activity than some of the other compounds when tested against rabbits. When many of the analogs were tested later against Norway rats, warfarin proved to be the most promising of the group. Since species differences do exist, it appears quite likely that, if the analogs were tested systematically against the roof rat, a poison more nearly suited to that species might be found.

\section{Summary}

A new laboratory method was devised for the rapid evaluation of multiple-dose, slowacting rodenticides with respect to required dosage, bait refusal, and speed and variability of action. With this method, it was found that, in general, wild Norway rats are most susceptible and roof rats least susceptible to each anticoagulant compound tested. Wild mice tend to resemble Norway rats in susceptibility, but they resemble roof rats in the high variability of response. The performance of warfarin was not excelled by the other anticoagulant compounds tested, although coumachlor, Diphacinone, and Pival were each about equal to warfarin against 1 or 2 species. PMP was distinctly inferior in performance. A short supply of animals prevented testing coumachlor against mice or Diphacinone against roof rats or mice.

\section{REFERENCES}

(1) Hayes, W. J., Jr., and Gaines, T. B.: Control of Norway rats with residual rodenticide warfarin. Pub. Health Rep. 65: 1537-1555, Nov. 24, 1950.

(2) Crabtree, D. G.: Raticidal potentialities of WARF-42. Soap and Sanit. Chemicals 26: 131-135, 147, February 1950.

(3) Doty, R. E. : Warfarin (Compound 42). A promising new rodenticide for cane fields. Hawaiian Planters' Record 54: 1-21 (1951). Also Preprint from the first issue of 1951.

(4) Bonnet, D. D., Mau, E. S. C., and Gross, B. : Cage tests with warfarin on the Hawaiian rat, Rattus hawaiiensis Stone, and the house mouse, Mus musculus Linn., in Hawaii. Pub. Health Rep. 66: 1734-1737, Dec. 28, 1951.

(5) Reiff, M., and Wiesmann, R.: Untersuchungen über ein neues Rodentizid mit kumulativer Wirkung auf Basis der Cumarin-Derivate. Acta trop. 8: 97-130 (1951).

(6) Bonnet, D. D., and Gross, B.: Susceptibility of Rattus hawaiiensis Stone to warfarin. Science 118: 44-45, July 10, 1953.

(y) Steiniger, F.: On the effectiveness of "Fumarin," a new anticoagulant, for combating rats and its tolerability for domestic animals. Nachrbl. deut. Pflanzenschutzdienst, Stuttgart 5: 167168, November 1953.

(8) Bentley, E. W., Hammond, L. E., and Taylor, E. J.: The comparative toxicity of 0.025 percent and 0.005 percent warfarin to Rattus norvegicus. Plant Pathol. 4: 120-123, December 1955 .

(9) Bentley, E. W., and Rowe, M.: Pival, an anticoagulant rodenticide. J. Hyg. 54: 20-27, March 1956.

(10) Robison, W. H., and Crabtree, D. G.: Fumarin, a new 4-hydroxycoumarin anticoagulant rodenticide. Agr. Chem. 11: 30-31, May 1956.

(11) Gates, R. L.: Diphacin-A new anticoagulant rodenticide. Pest Control 25: 14, 16, August 1957.

(12) U. S. General Services Administration: Rodenticide, anticoagulant, universal bait, concentrate. Interim Federal Specification O-R00497b (Int. FWS). Washington, D. C., 1958, 11 pp. 
(13) Overman, R. S., Stahmann, M. A., Heubner, C. F., Sullivan, W. R., Spero, L., Doherty, D. G., Ikawa, M., Graf, L., Roseman, S., and Link, K. P. : Studies on the hemorrhagic sweet clover disease. XIII. Anticoagulant activity and structure in the 4-hydroxycoumarin group. J. Biol. Chem. 153 : 5-24, April 1944.

\section{SUPPLY REFERENCES}

(A) Purina Laboratory Chow, Ralston Purina Co., St. Louis, Mo.
(B) Warfarin, Wisconsin Alumni Research Foundation, Madison, Wis.

(C) Coumachlor, Geigy Co., Inc., 89 Barclay St., New York 8, N. Y.

(D) Pival, Motomco, Inc., 89 Terminal Avenue, Clark, N. J.

(E) PMP, U. S. Fish and Wildlife Service, Denver, Colo.

(F) Diphacinone, Niagara Chemical Division, Food Machinery and Chemical Corp., Middleport, N. $\mathbf{Y}$.

\section{Specialized Training Courses in Environmental Health}

The following courses are scheduled for March 1959 by the Robert A. Taft Sanitary Engineering Center in Cincinnati, Ohio:

March 2-13. Basic Radiological Health. Fundamental technical knowledge needed for radiological health work, with stress on basic nuclear physics and chemistry. Prerequisite for several other courses.

March 2-13. Water Quality Management: Sanitary Engineering Aspects. Intensive training for sanitary engineers and others active in administration of water-quality management programs. Biological, chemical, and bacteriological phases included. Assignment to discussion panels made prior to the course on the basis of experience and interest.

March 16-20. Physical Analysis of Atmos. pheric Particulates. Emphasis on properties and physical behavior of particles and methods of sampling and evaluation. Laboratory exercises used in application of techniques.
March 16-25. Environmental Health Aspects of Nuclear Reactor Operations. Introduction to environmental health and safety aspects of nuclear reactor operations, especially off-site problems. Includes 3-day tour of reactor and waste disposal facilities at Oak Ridge National Laboratory, with lectures by ORNL personnel. Prior completion of basic radiological health course required.

March 23-27. Analysis of Atmospheric Inorganics. Broad, technical coverage of qualitative and quantitative analysis of pollutants, with emphasis on applicability and limitations of present methods. Includes laboratory practice.

Address applications to the Chief, Training Program, Robert A. Taft Sanitary Engineering Center, Public Health Service, 4676 Columbia Parkway, Cincinnati 26, Ohio, or the medical director in a regional office. 


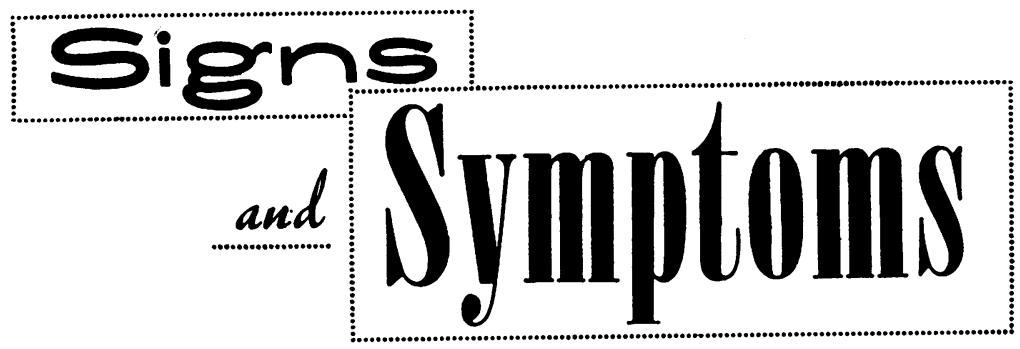

of trends in public health

The Medicine Man is a new 27minute sound film on food faddism and nutritional quackery. Prepared by the American Medical Association from Food and Drug Administration cases, the film depicts a television commentator's investigation of two types of nutrition "quacks": the "health" food lecturer and the door-to-door supplement salesman who makes unwarranted claims for his product.

A graduate Institute of Nutritional Sciences has been established at Columbia University for worldwide training of experts to combat malnutrition. Public health, science, and Ph.D. degrees will be offered, with opportunities for laboratory, clinical, and field research.

$$
\text { (1) }
$$

Japan reports $1,558,000$ births in 1957, compared with $2,678,000$ in 1947.

$$
\text { a }
$$

Iowa's campaign to "Save $\mathbf{1 0 0}$ Lives" a year has been such a success that insurance companies are cutting their rates. In 1 year, the traffic death toll was reduced by 21.7 percent, and during the last 5 months in 1958 automobile crashes were 10 percent less than in the same period in 1957.

$$
\text { a } \infty
$$

A report by the House Committee on Government Operations says the American consumer is being bilked out of $\$ 100$ million annually in the sale of so-called weight-reducing products.
The number of States and Territories with programs for mentally retarded children has grown from 4 to 44 in the last 3 years, the U. S. Children's Bureau reports.

\section{(1)}

The need for more discrimination in the use of penicillin was cited in the Chronicle of the World Health Organization, September 1958. The report calls for education of medical personnel and the public and for regulatory restrictions of sales. From 1943, when penicillin came into general use, through 1957, some 1,000 deaths from anaphylaxis due to penicillin occurred in the United States alone.

Arthritis sufferers with employment difficulties are for the first time being taught various jobs required in hospital operation. The 3-year $\$ 100,000$ vocational rehabilitation program is run by the New York Arthritis and Rheumatism Foundation in cooperation with the Long Island Jewish Hospital of New Hyde Park.

$$
\text { 《 } \quad 3
$$

What We should Know About Alcohol, a manual for teachers and group leaders by Mildred H. Weiss, clinical psychologist, Cleveland Center on Alcoholism, is offered for use with slides on alcohol education, by the Cleveland Health Museum.

$$
\propto \text { " }
$$

Antimony in lemonade stored overnight in a cheap, enamelware pitcher poisoned 100 picnicking children, reports the Philadelphia Health Department.
When health officers apply for the commitment of mental patients to hospitals, the applications are expeditious and inexpensive, avoid court procedure, and are less traumatic for patient and family, the Butte County (Calif.) Public Health Notes reports.

$$
\text { « } 》
$$

Following a report indicating that ground water supplies were being contaminated by synthetic detergents from cesspools in heavily populated areas, the Suffolk County Health Department (New York) tightened controls over the digging of private wells. No building permits will be granted without health department certification in areas which have no public water supply.

Private-duty nurses in Washington, D. C., were authorized by the Graduate Nurses Association to raise their basic fee to $\$ 18$ for 8 hours service on October 1 . The new schedule does not authorize extra charges for special cases or for evening duty.

A new edition of the New York State Department of Mental $\mathrm{Hy}$ giene's Blondie calendar covering the years $1959-60$ is now available for general distribution. The calendar contains 12 méntal health messages, to be applied to daily experience.

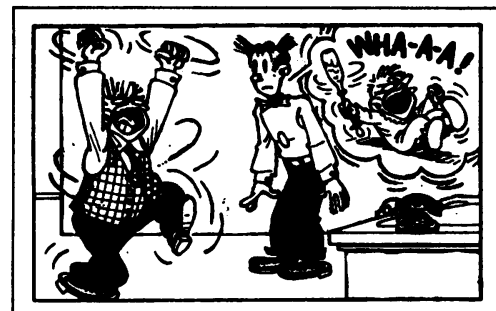

Don't let your emotions run you. You be the boss!

Temper tantrums and such are kid stuff. 1960

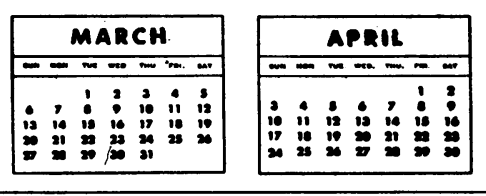

C King Features Syndicate, Inc. 